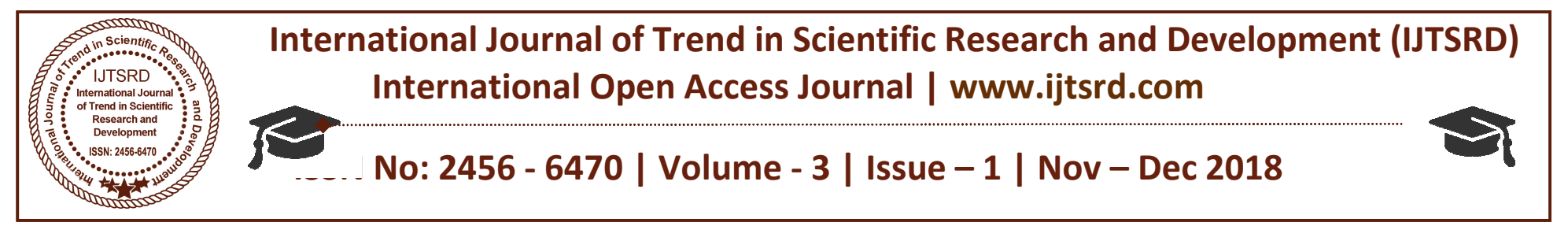

\title{
Study on the Effect of Yoga on Resting Cardiovascular Parameters and Cardiovascular Autonomic Functions
}

\author{
Dr. Sonika Choudhary ${ }^{1}$, Dr. Man Singh Choudhary ${ }^{2}$, Er. Pukhraj Choudhary ${ }^{3}$ \\ ${ }^{1}$ Assistant Professor, ${ }^{2}$ Former Add. Collector, ${ }^{3}$ Sr. Section Engineer \\ ${ }^{1}$ Department of Physiology, R.N.T. Medical College, Udaipur, Rajasthan, India \\ ${ }^{2}$ (Dev.) Rajasthan, India, ${ }^{3}$ (Indian Railway)
}

\begin{abstract}
Research studies have shown that yoga can modulate autonomic functions. Hence, the current study was designed to assess the effect of yoga on cardiac autonomic activity. 100 healthy volunteers (M78:F22) from age group 17-26 years were included in the study. They practiced some yogic exercises including Asanas, Pranayam \& relaxation techniques daily one hour for 3 months. Cardiovascular autonomic function tests parameters including Resting heart rate (HR), Blood Pressure (SBP, DBP), rate pressure product (RPP) and double product (DoP), heart rate response to deep breathing (E: I ratio), valsalva maneuver (VR) and pressure response to cold pressor test (CPT) were studied before and after 3 months of yoga training. Result showed significant reduction in heart rate $(\mathrm{p}<0.01), \operatorname{SBP}(\mathrm{p}<.05), \mathrm{RPP} \& \operatorname{DoP}(\mathrm{p}<.01)$ and E: I ratio increased significantly while valsalva ratio (VR) did not change significantly after the yoga training $(\mathrm{P}>0.05)$. In cold pressor test $(\mathrm{CPT})$ rise in SBP $(\triangle \mathrm{SBP})$ and rise in DBP $(\triangle \mathrm{DBP})$ was significantly decreased in response to cold water after 3 months of yoga training. These findings suggest that, Yoga training improved autonomic functions in healthy volunteers.
\end{abstract}

KEY WORDS: Yoga, Autonomic functions, E: I ratio, $V R, C P T$

\section{INTRODUCTION}

The word "yoga" comes from the Sanskrit root yuj, which means "to join" or "to yoke".

Yoga a psycho-somatic-spiritual discipline achieves union \& harmony between mind, body and soul and ultimately leads to union of individual consciousness with the Universal consciousness (1). These practices are believed to have originated in early civilization on the Indian subcontinent and have been practiced historically in India and throughout East Asia.

The most popular branch of yoga is Hatha Yoga, which consists of a combination of postural exercises (Asanas), relaxation and voluntary breathing exercise (Pranayamas).

Autonomic system regulates the functions of visceral organs in the body, which are not under voluntary control. Two components of autonomic system viz., sympathetic and parasympathetic nervous system act in a reciprocate manner to maintain the balance of visceral functions. Yoga can be inferred to unite the functions of these two limbs of autonomic nervous system to maintain the balance for obtaining the harmony or homeostasis of the physiological system (samatvamyogamuchyate, Patanjali's yoga sutra).

Scientific studies have shown that the practice of yoga decreases resting heart rate and blood pressure (2). Selvamurthy et al (3) found that six months of yoga resulted in an autonomic shift towards the parasympathetic nervous system. Mirabai et al (4) has reported that the regular practice of a set of yoga training blunted the sympathetic drive and lateralised the autonomic function towards parasympathetic control.

The effect of regular practice of yoga on cardiovascular autonomic functions is important to better understand its effects on healthy individuals and to provide the basis for the possible use of yoga techniques as alternative therapy. 
In this respect the present study evaluated the effect of regular practice of Yoga on Autonomic function test.

\section{Material and Method:}

This study was conducted on 100 healthy students and volunteers between age of 17-26 years of either sex (M78:F22) from Dr. S.N. Medical College, other academic colleges and yoga centres.

Subjects included in the study were non alcoholic, non smokers, not taking any type of medication and were having similar dietary habits.

Subjects involved in heavy physical exercise and previous experience of yoga training, history of any major medical illness and major surgery were not included in the present study.
Subjects were allocated to practice yoga for 3 months. The volunteers and students were briefed about the outcome of study and a written consent was obtained from them.

Subjects were given yogic training for 1 hour under the guidance of qualified yoga instructor for 3 months regularly. The yogic schedule includes - asanas (postural exercise), relaxation techniques and pranayma (breathing exercise).

Asanas were performed for $40 \mathrm{~min}$. duration. Each subject performed every asana 3 times. The asanas were followed by a meditation/ deep relaxation technique in shavasana (corpse posture) for $5 \mathrm{~min}$. \& pranayama (breathing exercise) was performed in the last 15 minutes. The set of asanas \& pranayama included in the course are listed in Table -1

\section{Table-1 Details of Yogic Practices}

\section{ASANAS}

\section{(A) Standing}

1. Ardhakatichakrasana (lateral arc pose)

2. Padahastasana (forward bend pose)

(B) Sitting

Ardhamatsyendrasana (half-spinal twist pose)

Pschimottanasana (back stretch pose)

(C) Lying on stomach (prone)

1. Makarasana (crocodile pose)

2. Bhujangasana (cobra pose)

3. Shalabhasanas (locust pose)

4. Dhanurasana (bow pose)

(D) Lying on back (supine)

1. Utthanpadasana (straight leg raising)

2. Ardhahalasana (plough pose)

3. Pavanmuktasana (wind relieving pose)

4. Setubandhasana (bridge pose)

(E) Deep Relaxation in Shavasana (Corpse Pose)

(F) Pranayama (Breathing Practices)

1. Kapalbhati Pranayama

2. Anulom-VilomPranayama

(alternate nostril breathing)

3. Bhramari (honeybee sound during expiration)

\section{Parameters:-}

Table-2 Anthropometric measurements

\begin{tabular}{|c|c|c|}
\hline Parameter & Pre & Post \\
\hline Height $(\mathrm{m})$ & $1.69 \pm 0.07$ & $1.69 \pm .07$ \\
\hline Weight $(\mathrm{Kg})$ & $60.63 \pm 8.91$ & $60.29 \pm 8.61$ \\
\hline BMI $\left(\mathrm{Kg} / \mathrm{m}^{2}\right)$ & $21.24 \pm 2.72$ & $21.07 \pm 2.58$ \\
\hline
\end{tabular}


First anthropometric characteristics (body weight, height, and BMI) were evaluated using an anthropometric scale. (Table-2) Then before starting yoga training \& after end of 3 months following parameters were measured.

Resting cardiovascular parameters: After 10 minutes of supine rest, arterial blood pressure (BP) was recorded using a standard mercury column sphygmomanometer and stethoscope.

Resting Heart rate (HR) was measured using an electrocardiograph (ECG) rhythm strip on limb lead II and calculated by dividing 1500 by the number of small squares between two $R$ waves in the ECG tracing.

Rate pressure product $[\mathrm{RPP}=(\mathrm{HR} \times \mathrm{SBP}) / 100]$ and double product $(\mathrm{Do} \mathrm{P}=\mathrm{HR} \times \mathrm{MP} / 100)$ were calculated for each recording. Three $\mathrm{BP}$ and $\mathrm{HR}$ recordings at 2-minute intervals were taken and the lowest of these values was included for the present study.

\section{Cardiovascular Autonomic function test:}

To measure the parasympathetic activity, deep breathing test (DBT), valsalva ratio (VR) and for sympathetic activity cold pressure test (CPT) was performed following the procedures described by Banister and Mathias (5). All these test employed in the study were simple, reliable and non-invasive.

I. Deep breathing test (DBT): The test was performed in supine position. Subject was asked to breathe deeply at a rate of 6 breaths per minute, allowing $5 \mathrm{sec}$ each for inspiration and expiration, by counting "IN-2-3-4-5-OUT-2-3-4-5" hand signal were also given to maintain the rate and timing of the breathing. Along with deep breathing ECG recording was also done in IInd limb lead. It was explained that breathing should be smooth, slow and deep.

The parasympathetic activity (heart responses to deep breathing) was measured by calculating E: I (Expiration: Inspiration) ratio.

$\mathrm{E}$ : $\mathrm{I}$ ratio $=$ average of maximum $\mathrm{R}-\mathrm{R}$ interval during expiration / average of minimum R-R interval during inspiration.

II Valsalva ratio (VR): For valsalva maneuver subject was allowed to sit in erect posture in a chair with a rubber clip over the nose. Subject was asked to blow out forcefully in rubber tube of mercury manometer and to create a pressure of $40 \mathrm{~mm} \mathrm{Hg}$ and maintain it for $15 \mathrm{sec}$. Simultaneously an ECG was recorded during $\mathrm{VM}$ and $30 \mathrm{sec}$ after finishing it in limb lead II. From the ECG recording, Valsalva ratio was calculated using the formula - Valsalva ratio $=$ longest R-R interval after maneuver / shortest R-R interval during maneuver.

CPT was done to assess sympathetic reactivity.

I Cold pressure test (CPT): The subject was asked to immerse his hand in cold water at $4-6^{0} \mathrm{C}$ up to the wrist joint for 2 minutes. After 2 minutes subject was allowed to remove the hand. Simultaneously BP was recorded on other arm before starting of the test and towards the end of the test. Increase in systolic and diastolic blood pressure from the baseline value (average of two values) to maximal value, known as the range or response $(\Delta)$, was obtained.

\section{Analysis of data}

Paired t test was used to compare the data. $\mathrm{P}$ value $<0.05$ was considered significant.

\section{Observation and Result:}

On comparing pre and post training data yoga training shows significant $(\mathrm{p}<0.01)$ reduction in resting heart rate.

Result shows reduction in both systolic and diastolic blood pressure but significant reduction $(\mathrm{p}<0.05)$ was only observed in systolic blood pressure after yoga training.

Yoga also shows significant reduction $(\mathrm{p}<0.01)$ in RPP and DoP.

Table-3 Cardiovascular Parameters before and after yoga training

\begin{tabular}{|c|c|c|}
\hline Parameter & Pre & Post \\
\hline Heart Rate (beats/min) & $77.69 \pm 8.57$ & $73.38 \pm 5.52$ \\
\hline $\mathrm{SBP}(\mathrm{mmHg})$ & $124.39 \pm 7.6$ & $121.26 \pm 6.79$ \\
\hline $\mathrm{DBP}(\mathrm{mmHg})$ & $76.04 \pm 6.7$ & $73.62 \pm 5.3$ \\
\hline RPP (units) & $96.69 \pm 12.65$ & $89 \pm 8.54^{* *}$ \\
\hline Do P (units) & $71.66 \pm 9.56$ & $65.70 \pm 6.22^{* *}$ \\
\hline
\end{tabular}

Yoga training resulted into significant increase in E: I ratio (heart rate response to deep breathing) while 
valsalva ratio (VR) during VM did not change significantly after the yoga training $(\mathrm{P}>0.05)$.

\section{Table-4 Cardiovascular Autonomic Functions before and after yoga training}

\begin{tabular}{|c|c|c|}
\hline Parameter & Pre & Post \\
\hline E: I ratio (DBT) & $1.42 \pm 0.16$ & $1.49 \pm 0.19^{*}$ \\
\hline VR & $1.69 \pm 0.29$ & $1.77 \pm 0.26$ \\
\hline$\Delta$ SBP $(\mathrm{CPT})$ & $16.73 \pm 5.45$ & $12.98 \pm 4.4 * *$ \\
\hline$\Delta \mathrm{DBP}(\mathrm{CPT})$ & $12.86 \pm 4.75$ & $8.8 \pm 3.19^{* *}$ \\
\hline
\end{tabular}

$* \mathrm{P}<.05$ on comparing pre and post yoga group

In cold pressor test (CPT) rise in systolic blood pressure $(\triangle \mathrm{SBP})$ was found to be significantly reduced from $16.73 \pm 5.45 \mathrm{mmHg}$ to $12.98 \pm 4.4 \mathrm{~mm} \mathrm{Hg}$ $(\mathrm{P}<0.01)$ and rise in diastolic blood pressure $(\triangle \mathrm{DBP})$ from $12.86 \pm 4.75 \mathrm{mmHg}$ to $8.8 \pm 3.19 \mathrm{~mm} \mathrm{Hg}$ $(\mathrm{P}<0.01)$.

\section{Discussion:}

Yoga training resulted in appreciable and statistically significant improvement in most of the parameters measured in this study.

Our results are also consistent with the findings of other workers who have reported beneficial effects of Yoga training on Cardiovascular Autonomic functions $(6,7)$.

Yoga training showed significant reduction in heart rate and it is attributed to increased vagal tone and decreased sympathetic activity $(8,9)$. Decreased sympathetic activity in turn reduces catecholamine secretion and also leads to vasodilation leading to improvement in peripheral circulation. It is also observed that regular yogic practices reduce basal metabolic rate and resting oxygen consumption (10). All these may be responsible for reduction in resting heart rate.

RPP and Do $\mathrm{P}$ are indirect measures of cardiac oxygen consumption and work done by the heart. In post training analysis there was a significant fall in cardio vascular parameters SBP, RPP and DoP. This may be understood as being a result of more relaxed state of mind leading to decrease in sympathetic tone coupled with a reduced load on heart as illustrated by decreased RPP and DOP.

Present study showed a significant $(\mathrm{P}<.05)$ increase in heart rate response to deep breathing (E: I ratio). Normally, in adults the difference in heart rate varies from 10-15 and a value less than 10 is regarded as abnormal. E: I ratio decreases with increasing age (5).

A significant rise in E: I ratio after yoga indicates an increase in vagal activity, as the change in heart rate during breathing is mainly due to the change in vagal activity (11). Our finding corroborate with the observations of Pal GK et al (6) and Mourya $\mathrm{M}$ et al (7).

Valsalva ratio (VR) indicate intact baroreceptors mediated increase or decrease in heart rate in response to Valsalva maneuver so this test is markers of parasympathetic reactivity and baroreflex function.

In our study valsalva ratio (VR) did not show any change after 3 months of training although increasing trend was observed in this parameters. This may be due to the shorter duration of training schedule, which was not adequate enough to cause changes in the sensitivity of baroreceptors to affect this parameter. Similar result was also shown by Pal GK et al (6) and Khanam et al (12).

After yoga training change in SBP and DBP $(\triangle \mathrm{SBP}$ and $\triangle \mathrm{DBP}$ ) during cold pressor test was found to be significantly reduced $(\mathrm{P}<0.01)$. This shows that practice of Yoga is well-demonstrated to reduce the physical effects of stress on the body (13). Madanmohan et al (14) and Sharma G et al (15) studied modulation of CPT-induced stress by shavasana wherein they found a significant reduction in BP. This reduction was explained on the basis of an increase in parasympathetic tone and reduction in sympathetic tone.

\section{Conclusion:}

The present study shows that 3 months yoga training produces a significant improvement in parasympathetic functions baroreceptor reactivity and decrease in sympathetic response to stress.

\section{References:}

1. Madanmohan (2008). Introducing Yog to Medical Students-The JIPMER Experience: Advanced Centre for Yoga Therapy, Education and Research.

2. Sahoo JK, Vatve M, Sahoo KD, Patil VV. Effect of specific yogasanas on cardiovascular autonomic function test. Pravara Med Rev. 2010; 5(1): 10-15. 
3. Selvamurthy W, Nayar H S, Joseph N T, Joseph S. Physiological effects of yogic practice. Nimhans Journal. 1983; 1 (1): 71-80.

4. Mirabai A, Sutnga T, Sarada N. A Study on the Effect of Yoga on Sympathetic Nervous System. Journal of Dental and Medical Sciences. 2017;16(5):13-16.

5. Bannister R, Mathias CJ. Investigations of autonomic disorders. Autonomic failure-A text look of clinical disorders of the autonomic nervous system, 3rd ed. San Franscisco: Oxford university press; 1992: 255-290.

6. Pal GK, Velkumary S, Madanmohan. Effect of short-term practice of breathing exercises on autonomic function in normal human volunteers. Indian J Med Res. 2004; 120: 115-121.

7. Mourya M, Mahajan AS, Singh NP, Jain AK. Effect of slow- and fast-breathing exercises on autonomic functions in patients with essential hypertension. J Altern Complement Med. 2009; 15(7): 711-717.

8. Wenger M. A. and Bagchi B.K. Studies of autonomic functions in practitioners of yoga in India. Behavioral science. 1961; 312-323.

9. Vempati RP, Telles S. Yoga-based guided relaxation reduces sympathetic activity judged from baseline levels. Psycho.Rep. 2002; 90: 487494.

10. Karambelkar P.V. and Bhole M. V.. Heart control and yoga practices. 1971 Yoga Mimansa, 53-65.

11. Ganong WF. Cardiovascular regulatory mechanism. Review of medical physiology. 20th ed. San Franscisco: McGraw-Hill; 2001: 575-579.

12. Khanam AA, Sachdeva U, Guleria R, Deepak KK. Study of pulmonary and autonomic functions of asthma patients after yoga training. Indian $\mathrm{J}$ Physiol Pharmacol. 1996; 40(4): 318-324.

13. Brown RP, Gerbarg PL. Sudarshan Kriya yogic breathing in the treatment of stress, anxiety, and depression: Part II: clinical applications and guidelines. J Altern Complement Med 2005; 11: 711-717.

14. Madanmohan, Udupa K, Bhavanani A B, Krishnamurthy N, Pal G K. Modulation of cold pressor induced stress by shavasan in normal adult volunteers. Indian J Physiol Pharmacol. 2002; 46 (3): 307-312.

15. Sharma G, Sharma LK, Sood S. Synergistic approach of applied physiology and yoga to combat lifestyle diseases. The Internet Journal of Alternative Medicine. 2009; 7 (1):1-6. 